\title{
Isolation and Identification of Phenol Degrading Halophilic Bacteria from Lonar Lake
}

\author{
B.A. Mehere, Priyanka A. Gupta* and Manashree D. Dongre
}

Department of Biochemistry and Biotechnology, Dr. Ambedkar College, Affiliated to RTM

Nagpur University, Nagpur, India

*Corresponding author

A B S T R A C T

\begin{tabular}{|l|}
\hline Key w o r d s \\
Lonar Lake, \\
Bioremediation, \\
Phenol degradation \\
and Halomonas \\
campisalis
\end{tabular}

\section{Introduction}

Phenols are the chemical compounds consisting of a hydroxyl group (-OH) bonded directly to aromatic hydrocarbon. They occur in various forms and are considered to be extremely toxic to humans (EPA, 2004). The presence of hydroxyl group makes it soluble in water since it can make hydrogen bonds with water (9 gram in $100 \mathrm{ml}$ water)(Morrison and Boyd,1992). However, the aryl group being hydrophobic, decreases its solubility. Phenolic compounds are serious river pollutants (EPA, 2004) and are known to have
Phenol and its components are extremely toxic and can easily be isolated from different industrial sewage such as oil refinery, petrochemical industry and mines, especially causing pollution in water bodies. Rivers and oceans are contaminated used for the elimination of phenol and its compounds, but today, bioremediation is preferable. The aim of this study is to isolate promising halophilic bacteria from Lonar Lake showing phenol degradation in wide $\mathrm{pH}$ range (neutral as well as alkaline). Different lates from Lonar Lake were tested for growth in presence of phenol as sole $\mathrm{C}$ source. The isolate growing in high phenol concentration was identified on basis of biochemical identification methods and 16s sequencing. Finally, the ability of bacteria to degrade different concentration of phenol was measured using culturing bacteria in different concentration of phenol from 0.3 to $1.0 \mathrm{~g} / \mathrm{l}$. and turbidity was measured after 24-48 days. The phenol degradation was estimated using Folin Lowry method after 48 hrs of inoculation. The isolated bacteria was identified as Halomonas campisalis. 
Phenolic pollution of ground water causes serious ecological problems. Hence, the permissible amount of phenol in industrial outgoing must not be more than $0.5 \mathrm{mg} / \mathrm{l}$. taking the above issues into consideration, elimination of phenol from the environment, especially from water and its resources, is of prime importance. Phenol can easily make its way in the human body when aquatic animals from polluted water are consumed as food. Sewage from factories contaminates water resources. Majority of rivers have become turbid and obscure due to dumping of sewage waste, chemicals, oily substances and other extraneous material. Rivers, lakes and oceans, all show certain degree of contamination. Routine physico-chemical methods used for the degradation of phenol are expensive to run, at the same time, they produce harmful intermediates. Today, Bioremediation is considered as a new tool to eliminate environmental pollution (EPA, 2004). The metabolism of aromatic compounds, particularly phenol and its derivatives, has been intensively studied in prokaryotic microorganisms. Numerous phenol degrading micro-organisms have been isolated from different sources. Bacteria (such as Pseudomonas spp., Acinetobacter spp.), yeast (such as Pleurotutus ostreatus, Candida tropicalis, Trichosporon cutaneum and Phanerochaete chrysosporium) and fungi (like Fusarium flucciferum and Aspergillus fumigates) can degrade phenol; although, among algae, Ochromonasdanica can degrade phenol while meta pathway (Ariana et al., 2004; Xiangchun et al., 2004; Godjevargova et al., 2003). Chitra et al., (1995), has studied the removal of phenol using a mutant strain of Pseudomonas. In oceans, oil spills and phenolic pollutants pose major problems. So, there is a need to study bacteria which can degrade phenol even at high $\mathrm{pH}$ and salt concentrations. The aim of this study is to isolate and identify the phenol degrading halophilic bacteria from water of Lonar Lake which can degrade phenol in neutral as well as alkaline $\mathrm{pH}$ range. Also, the study aims at assaying the elimination level of phenol by isolated bacteria.

\section{Materials and Methods}

\section{Sample collection}

Water samples were collected directly into sterile bottles from the Lonar Lake. To arrest bacterial growth, samples were stored at $4^{\circ} \mathrm{C}$ in the laboratory until used for isolation of the strains.

\section{Enrichment and isolation of bacteria}

Enrichment cultures and techniques to isolate moderate to extremely halophilic microorganisms were performed in Halophilic Agar/ broth medium. pH was adjusted to $7.2 \pm 0.1$ prior to autoclaving. Enrichment cultures were subcultured several times with different $\mathrm{NaCl}$ concentrations $(0 \%, 5 \%, 10 \%$, $20 \%$ ) but under similar conditions. Aliquots (100 $\mu$ l) of 10-3-10-6 dilutions were plated on to agar medium. Following incubation at $37^{\circ} \mathrm{C}$ for two weeks, growth was observed in a flask. With serial dilution technique, different colonies were picked and streaked several times to obtain pure cultures.

\section{Identification of phenol degrading bacteria}

The isolates were allowed to grow in media containing phenol as the sole $\mathrm{C}$ source. The isolate showing growth in the given condition was selected for further studies.

\section{Effect of $\mathrm{pH}$ and salt concentration on selected isolate}

After a period of 24 days of inoculation, different $\mathrm{pH}$ range (6 to 12), salt concentrations (5\% to $25 \%$ ) and OD were taken at $600 \mathrm{~nm}$. 


\section{Characterization and Identification}

Selected isolates were grown on selective media and were chosen for further characterization. Isolates were examined for colony and cell morphology. These characteristics were described from the growth of cultures at optimum temperature, $\mathrm{pH}$ and salt concentration. In biochemical tests, Catalase test, Amylase, Oxidase, Citrate, Urease, Indole test, Tryptophan Deaminase, Voges Proskauer, Fermentation/oxidation (lactose, sucrose, fructose) were performed. Different staining and biochemical tests were followed using standard procedure (Aneja, 2003):

\section{Gram staining}

Gram stain is a differential stain used to differentiate bacteria into two groups, Gram positive bacteria and Gram-negative bacteria. The concept behind the technique is that, Gram positive cell wall has a strong attraction for crystal violet when iodine is applied and therefore will retain the crystal violet and remain purple after decolorizing, while Gramnegative bacteria will become colourless after decolorizing with alcohol and counterstaining with Safranin will make them appear pink.

\section{Catalase test}

The glass slide was held at an angle while a few drops of $3 \%$ hydrogen peroxide were allowed to flow slowly over the culture. The emergence of bubbles from the organism was noted. The presence of bubbles was an indication of a positive test denoting the presence of enzyme catalase. If no gas is produced, it is a negative reaction.

\section{Amylase test}

For this test, isolate was point inoculated on starch agar plates and incubated at $37^{\circ} \mathrm{C}$ for two days. After incubation, iodine solution was poured on the agar and examined for hydrolysis of starch by the production of clear zone around the microbial growth.

\section{Urease test}

Urease test is performed by growing the test organisms on urea broth or agar medium containing the $\mathrm{pH}$ indicator phenol red (pH6.8). During incubation, microorganisms possessing urease will produce ammonia that raises the $\mathrm{pH}$ of the medium/broth. As the $\mathrm{pH}$ increases, the phenol red changes from a yellow colour ( $\mathrm{pH}$ 6.8) to a red or deep pink colour. Failure of the development of a deep pink colour due to ammonia production is an evidence of lack of urease production by the microorganisms.

\section{IMViC}

Indole Test: Tryptophan is an essential amino acid that can undergo oxidation by the means of enzymatic activity of bacteria and gets converted into metabolic products (indole, pyruvic acid and ammonia), which is mediated by the enzyme tryptophanase. Kovacs reagent is added to detect the presence of indole producing cherry red colour. The colour is produced by the reagent composed of $\mathrm{p}$ dimethyl amino-benzaldehyde. Absence of red coloration demonstrates that the substrate tryptophan was not hydrolysed and indicates that it is indole negative.

Methyl red test: All enteric microorganisms ferment glucose and produce organic acids. In the $\mathrm{pH}$ range of 4 , methyl red indicator which is used in this test will turn red, indicating of a positive test.

At a $\mathrm{pH}$ of 6 , still indicating the presence of acid but with a lower hydrogen ion concentration, the indicator turns yellow and is a negative test. 
Voges Proskauer test: This test determines the capability of some micro-organisms to produce non-acidic or neutral end products, such as acetyl methyl carbinol, from the organic acids that results from glucose metabolism. Baritt reagent used in this test consists of a mixture of alcoholic alphanapthol and potassium hydroxide solutions. Detection of acetylmethyl carbinol requires the end product to be oxidized to a diacetyl compound. This reaction occurs in the presence of alpha napthol catalyst and a guanidine group that is present in the peptone of MR-VP medium. As a result, a pink complex is formed which imparts a rose colour to the medium.

\section{Citrate utilization test}

Some micro-organisms are capable of using citrate as a carbon sources for energy in the absence of fermentable glucose or lactose. This ability depends on the presence of citrate permease that facilitates transport of citrate in the cell. During this reaction, the medium becomes alkaline and the carbon dioxide that is generated combines with sodium and water to form sodium carbonate, an alkaline product.

The Bromothymol blue indicator incorporated into the medium, changes from green to Prussian blue due to the presence of carbonate. After incubation, citrate positive culture is identified by the presence of growth on the surface of slants, which is accompanied by blue coloration. Citrate negative will show no growth and the medium will remain green.

\section{Carbohydrate fermentation}

Fermentation of carbohydrates such as glucose, sucrose and lactose is carried out by microorganisms, under anaerobic condition in which a Durham tube is placed in inverted position to trap the gas bubbles formed by the production of gas. The fermentation broth contains ingredients of nutrient broth, a specific carbohydrate and a $\mathrm{pH}$ indicator (phenol red), which is red at neutral $\mathrm{pH}$ (7) and turns yellow at or below a $\mathrm{pH}$ of 6.8 due to production of an organic acid.

\section{6s sequencing}

16s sequencing of the bacterial DNA was performed for identification of the isolate.

\section{Growth assessment of isolated bacteria in different concentration of phenol with optic absorption survey}

In this method, an optic absorption study was used to isolate the best phenol degrading species from phenol degrading bacteria. About $20 \mathrm{ml}$ of phenol broth media was poured into the separated Erlenmeyer flask (with different concentrations of phenol). This was followed by addition of $5 \mathrm{ml}$ media containing bacteria to each tube. For each bacteria, 8 Erlenmeyer flasks (with $0.3-1 \%$ phenol) were considered. In the control media, there was just a base media and a specific species, but without phenol. Media was incubated for $48 \mathrm{~h}$ at $37^{\circ} \mathrm{C}$ and 200rpm. Their absorbed mixture was read at $600 \mathrm{~nm}$ (Ali et al., 1998).

To examine the degradation of phenol, the flasks containing $50 \mathrm{ml}$ liquid medium were inoculated with equal volume of inoculum $(1 \times 105$ conidia/ml medium) and agitated on a shaker at $240 \mathrm{rpm}$ and $30^{\circ} \mathrm{C}$. Samples were taken after 48 hours of inoculation and centrifuged at $5000 \mathrm{rpm}$ for $20 \mathrm{~min}$ to separate the cells. Phenol degradation was determined in cell-free extracts and in the liquid phase of the culture media after $48 \mathrm{~h}$ of degradation process. Cells were harvested, washed twice in 50mMTris- $\mathrm{SO}_{4}$ buffer, $\mathrm{pH} 7.5$ and broken by grind and then cell debris were removed by centrifugation at $5000 \mathrm{~g}$ for $20 \mathrm{~min}$. The cleared supernatant solution was used for protein assays. Lowry method was used to 
determine phenol concentration in observed:

supernatant.

\section{Results and Discussion}

After several dilutions and subculturing in the liquid as well as solid medium, colonies were isolated in the enrichment medium. Various Halophilic strains were isolated under aerobic conditions from the sample. These strains were examined for phenol degradation.

The isolate showing maximum growth (by visual observation) in selective media with phenol was selected and its characters are observed as follows:

Colonies were circular, smooth, convex and were found to be translucent.

Effect of Optimum growth occurred at $10 \%$ and $20 \% \mathrm{NaCl}(\mathrm{w} / \mathrm{v})$ at $37^{\circ} \mathrm{C}$, and $\mathrm{pH} 7$, suggesting that these isolates should be considered as halophilic according to the definition of Ventosa et al., 1998.

The isolate was found to be gram negative, rod shaped. The growth conditions of all the isolated strains were optimized for $\mathrm{pH}$ and salt

\section{Tolerance}

The purpose of optimization of the strains was to find their optimum growth in different $\mathrm{pH}$. From the results, it was concluded that the halophilic bacteria species grow best at 9-11 $\mathrm{pH}$.

Similarly $\mathrm{NaCl}$ tolerance was checked and it grow best in the range of $10-20 \%$ at temperature $37^{\circ} \mathrm{C}$.

\section{Biochemical tests}

Isolated strain was tested for Biochemical characteristics and following results were

\section{Catalase test}

Isolate was found to be catalase negative as no bubble were produced.

Amylase test: it was found to be Amylase positive as it showed clear zones around the colonies by addition of iodine solution.

Urease Test: It was found to be urease positive as the media color changes from yellow to pink.

\section{IMVIC test}

Indole Production: it showed positive indole production test.

Methyl Red: it didn't showed methyl red positive test

Voges Proskauer Test: VP test was positive as pink color was observed in to Carbohydrates.

Citrate utilization: citrate utilization test positive as the color of media turned blue.

Fermentation of carbohydrates: Lactose: it showed fermentation of lactose with production of lactic acid and gas.

Sucrose: It showed gas and acid production.

Maltose: it didn't show acid production

16 s sequencing was done to confirm the species of the isolate, results of which confirmed the isolate to be Halomonas campisalis.

Halophilic bacteria grow better at the temperature of $28-37^{0} \mathrm{C}$ and at $\mathrm{pH} 7.0-8.0$ on media supplemented with $520 \% \mathrm{NaCl}$ concentration. Our study agreed with the study 
of Hongyu et al., (2009) who isolated the growth of these microorganism at the halophilic microorganism from ponds of temperature of $35-40^{\circ} \mathrm{C}$ and at $\mathrm{pH} 7.08 .0$ with China and Karak region and observed the 20-30\%(w/v) $\mathrm{NaCl}$.

Fig.1 Growth curve of the isolate

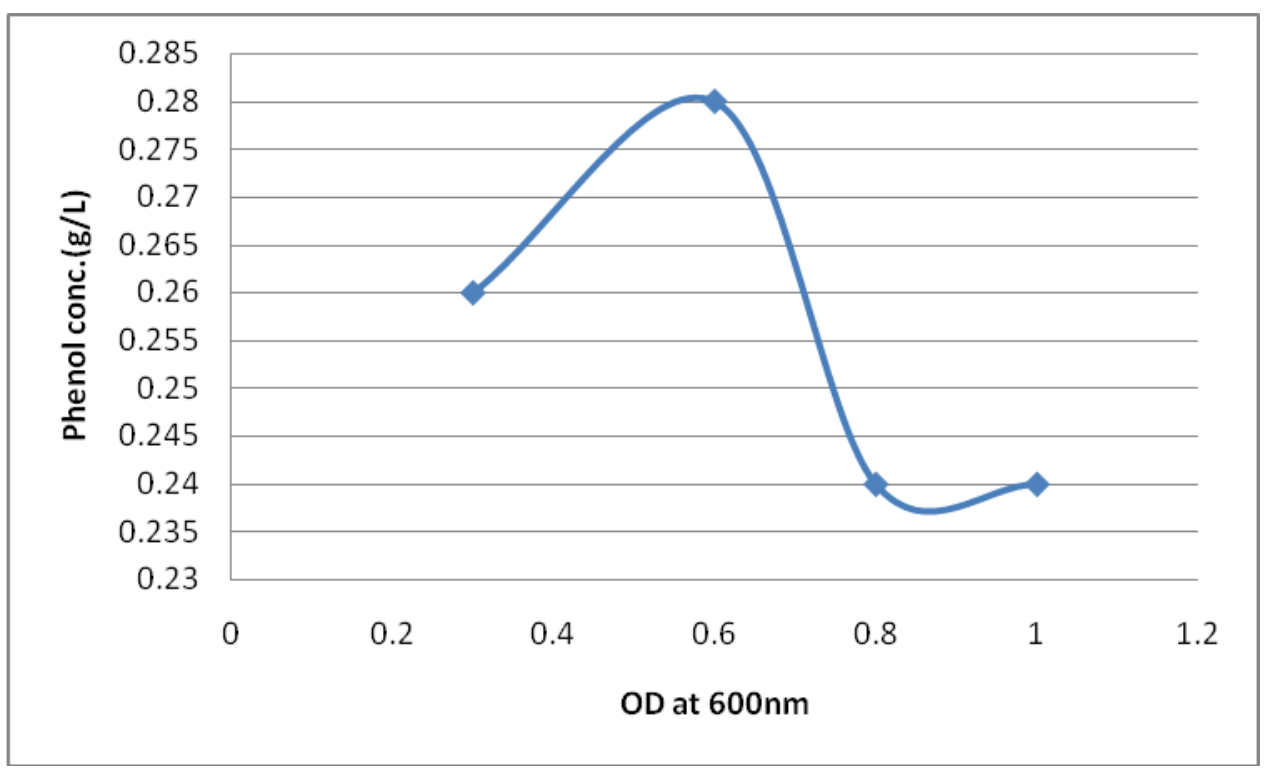

Fig.2 Elimination curve of phenol for the isolate

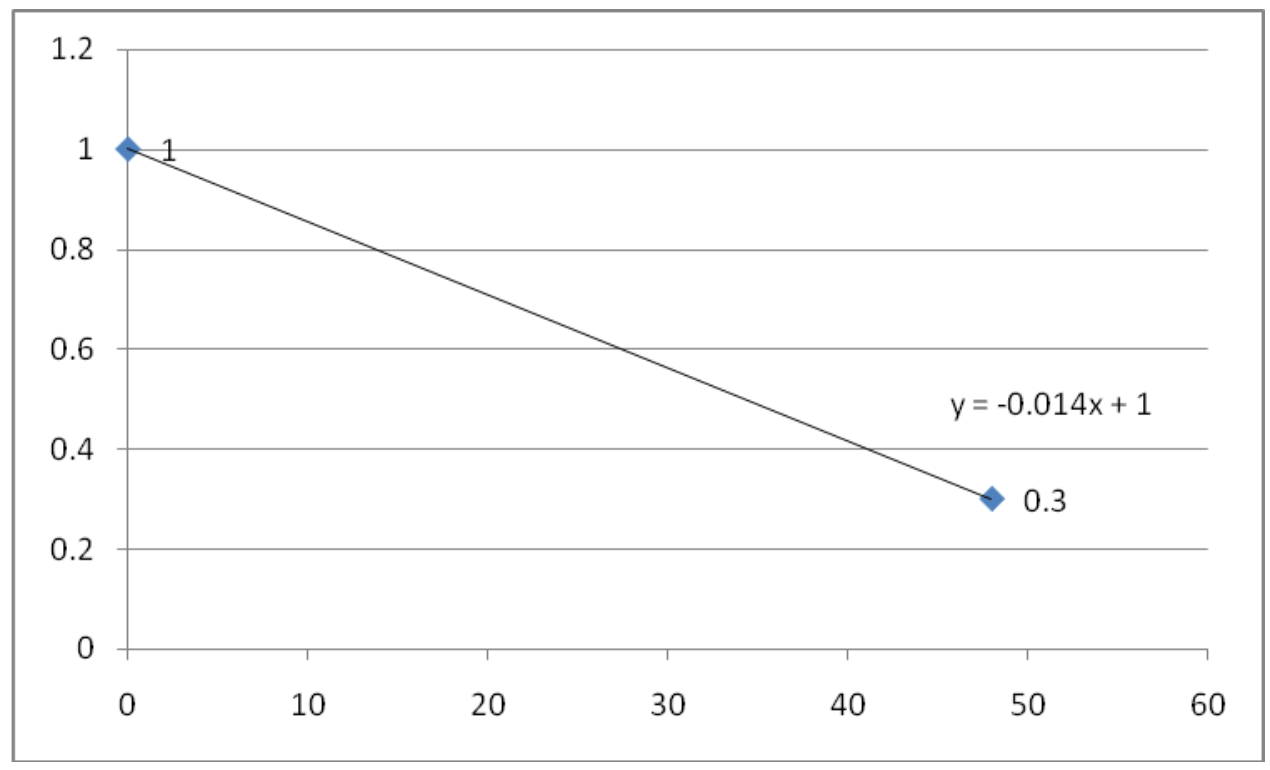

These properties offer significant advantage to study the activity and metabolism of halophiles at various salt concentration. Halotolerance of many enzymes derived from halophilic microorganisms can be exploited were as enzymatic transformation are required to function at low water activities, such as in the presence of high salt concentration (Kamekaru, 1986). Halophiles have the distinctive advantage to grow in environment 
having high salt concentration where other potential microorganisms fail to survive. This offers a multitude of potential applications in various fields of biotechnology.

Evaluation of growth at different phenol concentration: the result of the test is given in figure 1 . The isolate showed best growth at phenol conc. $0.6 \%$.

Phenol degradation rate was studied in $48 \mathrm{hrs}$ of inoculation. The result is as shown in figure 2 . The degradation rate $(\mu)$ is found to be $0.875 \mathrm{~g} / \mathrm{min}$.

Different methods have been used for the elimination of phenol, but the use of bacteria can be one of the cheap, operative and secure methods. Bacteria with rapid reproduction in the presence of phenol and its compound have shown extraordinary ability in phenol elimination. So with isolation, purifying and growing of species which has high ability of phenol elimination, they can be used in areas with phenol pollution. Different bacteria of different genus have been isolated as phenol degrading. Most of them, which chiefly belong to family Pseudomonaceae, are gram negative. Kounty et al., (2003) isolated phenol degrading bacteria from Siberia soils. Eduardo et al., (2000) report a bacterium Alcaligenes faecalis and yeast Candida tropica, which could degrade the phenol and still had a high salt concentration tolerance $(15 \%)$.

In this study, phenol degrading bacteria, which was isolated from Lake Lonar (soda lake), from genus Hlaomonas which is in agreement with the result of other researchers.

Isolated phenol degrading species mostly have a potential in phenol degrading. Considering the evaluated study and results of this study, it could be concluded that phenol degrading bacteria Halomonas campisalis, had a high salt concentration tolerance (15\%). Enzymes of such organisms such as new isomerases and hydrolases have their own significance due to their potential to remain active and stable in high salt contents. Such potential halophiles can be used in bioremediation or degradation and transformation of range of organic pollutants such as phenol in pond, lakes, streams, rivers and oceans.

\section{References}

Ali S, Lafuente RF, and Cowan DA 1998. Meta-pathway degradation of phenolics by Thermophilic Bacilli. Enzyme Microb. Technol. 23:462-468.

Aneja, K. R. 2003. Staining and biochemical techniques. Edition 4th.Experiments in microbiology, Plant Pathology and Biotechnology.

Ariana F, Elke B and Thomas B 2004. Rapid monitoring of the biodegradation of phenol-like compounds by the Candida maltose using BOD measurements. Int. Biodeterior. Biodegrad. 54: 69-76.

Chitra S, Sekaran G, Padmavathi S, Gowri C. Removal of phenol from waste water using a biocatalyst. In: Proceedings of the National Symposium Frontiers in Applied Environmental Microbiology. 1995. p. 74-7.

Eduardo A, Bastos R, Moon D 2000. Salt tolerant phenol-degrading microorganisms isolated from Amazonian soil sample. Appl. Environ Microbiol. 174: 346-352.

Godjevargova T, Ivanova D, Alexieva Z, and Dimova N 2003. Biodegradation of toxic organic components from industrial phenol production wastewater by free and immobilized Trichosporon cutaneum R57. Process Biochem. 38: 915-920.

Hongyu, W., L. Yang, L. Shen, B. Hu, L. Zongyun and J. Qijiang. 2009. Isolation 
and characterization of culturable halophilic Microorganisms of salt ponds in Lianyungang, China. World Journal of Microbiology and Biotechnology, DOI 10.1007/s11274-009-0068-5.

Kamekura, M. 1986. Production and function of enzymes from eubacterial halophiles. FEMS Microbiological Reviews. 39: 145150.

Koutny M, Ruzicka J, Chlachula J 2003. Screening for phenol degrading bacteria in the pristine solids of south Siberia. Appl. Soil Ecol. 23: 79-83.

Morrison RM, Boyd RN 1992. Organic chemistry, 6th ed. 1069-1098.

Powlowski J and Shingler V 1994. Genetic and biochemistry of phenol degradation by Pseudomonase sp. CF600.

Biodegradation, 5: 219-236.

The Environmental Protection Agency (EPA) 2004. Collation of toxicological data and intake values for humans. EPA Report. pp. 44-64.

Ventosa, A., Nieto, J. J. and Oren, A. 1998. Biology of moderately halophilic aerobic bacteria. Microbiol Mol Biol Rev 62, 504-544.

Xiangchun Q, Hanchang S, Yongming Z 2004. Biodegradation of 2, 4dichlorophenol and phenol in airlift inner-loop bioreactor immobilized with Achromobacter sp. Sep. Purif. Technol. 34: 97-103.

\section{How to cite this article:}

Mehere, B.A., Priyanka A. Gupta and Manashree D. Dongre. 2018. Isolation and Identification of Phenol Degrading Halophilic Bacteria from Lonar Lake. Int.J.Curr.Microbiol.App.Sci. 7(01): 2501-2508. doi: https://doi.org/10.20546/ijcmas.2018.701.300 